\title{
The effects of study-task relevance on perceptual repetition priming
}

\author{
JON B. HOLBROOK and PRESTON R. BOST \\ Vanderbilt University, Nashville, Tennessee \\ and \\ CAROLYN BACKER CAVE \\ University of Southampton, Southampton, England
}

\begin{abstract}
Repetition priming is easily elicited in many traditional paradigms, and the possibility that perceptual priming may be other than an automatic consequence of perception has received little consideration. This issue is explored in two experiments. In Experiment 1, participants named the target from a four-item category search study task more quickly than the nontarget study items at a later naming test. Experiment 2 extended this finding to conditions in which stimuli were individually presented at study. In three different study tasks, stimuli relevant to study-task completion elicitedpriming on a later test, but stimuli presented outside the context of a task did not. In both experiments, recognition was above chance for nonrelevant stimuli, suggesting that participants explicitly remembered stimuli that did not elicit priming. Results suggest that priming is sensitive to study-task demands and may reflect a more adaptive and flexible mechanism for modification of perceptual processing than previously appreciated.
\end{abstract}

The term implicit memory encompasses a variety of phenomena (e.g., semantic priming, classical conditioning) whose common feature is the influence of prior episodes on behavior without effortful, or explicit, retrieval of those episodes (for reviews, see Richardson-Klavehn \& Bjork, 1988; Squire et al., 1993). The recent "golden age" of implicit memory (Schacter, 1992) has seen a particular focus on one type of implicit memory: repetition priming, in which a single exposure to a stimulus during a study session (Treisman, 1992) leads to faster or more accurate processing of that stimulus at a later test (Tulving \& Schacter, 1990). For example, previously viewed pictures are identified more quickly than are pictures being presented for the first time (e.g., Lachman \& Lachman, 1980; Mitchell $\&$ Brown, 1988). Considerable evidence indicates that priming in many tasks (e.g., identification tasks) is a kind of perceptual memory, reflecting facilitated reprocessing of the perceptual features of stimuli (see Gabrieli et al., 1999). For example, priming from one symbolic form at study to another at test (i.e., words and pictures) is reduced relative to within-form priming (e.g., Kroll \& Potter, 1984; Srinivas, 1993; Warren \& Morton, 1982). Similar findings

This work represents the merging of two distinct research projects by J.B.H. and P.R.B., who each contributed equally to this study. This research was supported by a Young Investigator Award from the Office of Naval Research, Grant N00014-93-0578,to C.B.C. We thank Wendy Schnee, Amy Gould, Rebecca Keller, Belinda Buchanan, and Tania Colavita for assistance in subject testing, and Jeffery Franks, Timothy McNamara, Randolph Blake, and Kyle Cave for valuable comments on earlier drafts of this article. P.R.B. is now at Wabash College. Correspondence should be addressed to J. B. Holbrook, NASA Ames Research Center, Mail Stop 262-4, Moffett Field, CA 94035 (e-mail: jholbrook@mail.arc.nasa.gov). prevail when stimuli shift between the auditory and visual modalities (e.g., Blaxton, 1989; Jacoby \& Dallas, 1981; Roediger \& Blaxton, 1987).

This evidence for a perceptual component to priming initially suggested that priming would display a high level of perceptual specificity - in other words, that priming would be reduced by any change in the perceptual attributes of the stimulus (Tulving \& Schacter, 1990). Not all findings, however, have consistently pointed to a perceptually specific mechanism. Effects of perceptual modifications on priming in word paradigms have been mixed (see Graf \& Ryan, 1990, for a review); however, there is evidence that word priming is invariant across perceptual changes barring the use of extremely unusual typefaces or tasks that require scrutiny of perceptual features (Graf \& Ryan, 1990; Johnson, 2000). Priming for pictorial stimuli is generally unaffected by a broad range of perceptual manipulations such as changes in size, location, direction of face, color, and illumination (e.g., Biederman \& Cooper, 1991a, 1991b, 1992; Cave, Bost, \& Cobb, 1996; Cooper, Schacter, Ballesteros, \& Moore, 1992). Instead, priming for objects (in commonly used test tasks) seems to rely critically on the repetition of structure, or the placement of a set of parts in particular spatial relations (e.g., Schacter, Cooper, \& Delaney, 1990). This conclusion is consistent with a number of studies showing that manipulations of pictorial exemplars (e.g., Bartram, 1974; Biederman \& Cooper, 1991a, 1991b; Cave et al., 1996; Cave \& Squire, 1992; Warren \& Morton, 1982) or rotation in depth (Biederman \& Gerhardstein, 1993) reduce priming in an object identification paradigm, perhaps because they affect the ability to extract the basic shapes of objects. 
Because object recognition also relies on the extraction of object structure (see Humphreys \& Riddoch, 1987; Riddoch \& Humphreys, 1987), the priming literature has seen the development of "structuralist" theories (for extended discussion, see Bruce, Carson, Burton, \& Ellis, 2000) that describe perceptual priming for objects as a byproduct of object recognition (e.g., Biederman \& Cooper, 1991a). According to such theories, object priming is a fixed indicator of object recognition processes; consequently, it is sensitive to information needed for basiclevel object recognition (i.e., structure), but insensitive to information not required for this purpose (i.e., size, left/right reflection). This logic has provided justification for using priming as a methodological tool to investigate object recognition. For instance, priming paradigms have been used to determine the role of geon representations (Biederman \& Cooper, 1991b) and viewpoint dependence (Biederman \& Gerhardstein, 1993) in object recognition.

One alternative to structuralist theories is that priming for objects is sensitive to structural information not because it is hardwired to object recognition processes, but because the study tasks used to induce priming often do not require analysis other than basic object recognition. For example, using picture naming (e.g., Mitchell \& Brown, 1988 ) as a study task does not typically require attention to the color or size of the object. Study tasks requiring a focus on other types of information might reveal priming effects that are sensitive to, for example, size (Srinivas, 1996) in lieu of, or in addition to, structural information. This view is generally consistent with transfer-appropriate processing (TAP; e.g., Blaxton, 1989; Roediger, Weldon, $\&$ Challis, 1989) in that the "representation" supporting priming is a reflection not of a fixed process or system but rather of the particular processes engaged during the study session.

Some recent experimental evidence has suggested that the sensitivity of priming to some stimulus characteristics is not fixed, but variable. Despite previous demonstrations of size invariance (Cooper et al., 1992), Srinivas (1996) has shown that priming in picture naming can be sensitive to stimulus size in the context of study and test tasks that require size judgment. Presumably, the task demand in this study made sensitivity to size useful in the context of task performance and resulted in priming that was sensitive to this attribute. Similarly, Johnson (2000) found that changes in word orientation reduced priming when the study task required lexical decision and orientation judgment, but not when the study task required only lexical decision.

The notion that priming is tuned to task requirements yields an interesting prediction: If repetition priming is sensitive primarily to the information that is important for study-task solution, perhaps priming will be reduced or eliminated for entire stimuli that are perceived at study, but are not directly relevant to a study task. Such a finding would be conceptually similar to previous findings of invariance in object priming, in which some types of information (e.g., size, orientation, color, etc.) were evidently perceived at study but did not influence priming (e.g.,
Cooper et al., 1992). Again, this prediction is broadly consistent with TAP; if a stimulus is not critical to processing at study, there is less chance that any test task could replicate the processing of that item.

There is some evidence from studies of words that simply reading a word at study is not always sufficient to induce priming for the word at test. Oliphant (1983) found that priming occurred for words that had initially been presented within the context of the experiment but not for words from the instruction set. Other researchers have also found that words from sentences do not always prime in perceptual tests (Levy \& Kirsner, 1989; MacLeod, 1989, Experiment 1). This pattern of results mirrors the task requirements. The task in many perceptual implicit tests is to focus on individual words; the task when reading text is to understand the meaning of the sentences, in which case retaining the perceptual information about particular words is less important. The results are therefore consistent with the idea that repetition priming for words is linked to study-task requirements. The present study investigated the possibility that perceptual priming for pictures would be reduced or eliminated if they were not important to the completion of a task at study.

\section{EXPERIMENT 1}

To examine the influence of task relevance on priming and on explicit memory, Experiment 1 was conducted using four-picture study arrays, which allowed the creation of a study task in which participants would perceive some stimuli as task relevant and others as task irrelevant. For some participants, this study task was followed by a test of implicit memory, and for other participants, it was followed by a test of explicit memory.

Study arrays contained a single task-relevant stimulus: a target, defined by its membership in a category. The participants' task at study was to name this target item as quickly and accurately as possible. This task requires that participants respond to one item, but involves perception of some irrelevant stimuli (nontargets). If priming is dependent on the focus of the study task, priming should occur only for targets. If priming is not dependent on task relevance, priming should occur for nontargets as well as targets.

The priming task in Experiment 1 (as well as Experiments $2 \mathrm{~A}$ and $2 \mathrm{~B}$ ) was a variation of picture naming in which participants receive exposure to pictures at study, then name those stimuli along with new pictures at test. Participants generally name previously perceived pictures more quickly than they name new stimuli (Mitchell \& Brown, 1988). This paradigm is attractive because it produces robust priming effects that are independent of explicit memory (Cave \& Squire, 1992; Mitchell \& Brown, 1988). In addition, priming in picture naming has been shown to have a significant perceptual component (e.g., Biederman \& Cooper, 1992). Because picture naming is a speeded, well-practiced task that does not invite the strategic assessment of memory, it provides a reasonable alternative to some nonspeeded "implicit" memory tasks, such 
as word-fragment completion, that have been shown to be correlated with explicit memory measures (Perruchet \& Baveux, 1989). Recent research has demonstrated the value of speeded tasks in minimizing strategic retrieval (Horton, Wilson, \& Evans, 2001).

Because a failure to detect priming might reflect a simple failure to perceive nontarget stimuli at study, one group of participants performed an explicit yes/no recognition task at test as a means of assessing whether nontargets were perceived in the category search study task. Though explicit memory in the absence of significant implicit memory would reverse the typical pattern of dissociation (for review, see Richardson-Klavehn \& Bjork, 1988), similar dissociations have been observed in studies of perceptual specificity, in which participants are often explicitly sensitive to attributes that do not influence priming (Cooper et al., 1992).

\section{Method}

Participants. Participants in all experiments were Vanderbilt University undergraduates naive to the purposes of the study. All were native English speakers and had normal or corrected vision. There were 60 participants in Experiment 1. Following identical study phases, 40 participants performed a naming test and 20 performed a recognition test.

Materials and Design. Experiments were conducted on a Macintosh IIci computer using PsyScope software (Cohen, MacWhinney, Flatt, \& Provost, 1993). A microphone connected to the computer was used to record participants' oral responses.

The stimuli were 240 pictures from the set of line drawings of common objects created by Snodgrass and Vanderwart (1980) and digitized by Brooks (1985). These pictures were placed in 19 categories that were given one-word names (e.g., transportation, animal).
The 48 study stimuli each consisted of an array of four pictures, as shown in Figure 1. Each of these arrays contained one "old" picture that would appear later at test (the particular picture that reappeared at test varied across participants). Old pictures were equally divided between "targets," which were named at study, and "nontargets," which were not. Pictures were placed in arrays in such a way that the test items would come equally often from each of the four array positions.

Because the set of old stimuli (pictures appearing at both study and test) comprised one fifth (48 out of 240) of the entire set of pictures for any given participant, the stimuli were divided into five groups of 48 pictures that were equated on average name agreement ratings based on the Snodgrass and Vanderwart (1980) norms (range: $0.536-0.539$ ). The members of each of the 19 categories were equally divided among the five groups to ensure that the groups were also equated on category membership. These five groups were rotated across conditions in such a way that across 5 participants, every stimulus appeared in the old and new conditions. (For each participant, three groups served as filler objects, supplying pictures in the study arrays that would not appear again at test.) Further, because of the subdivision of old pictures into targets and nontargets, complete counterbalancing required that each group of pictures be rotated twice through each condition. Across 10 participants, therefore, each picture appeared in every condition: new at test (twice), old target (once), old nontarget (once), and untested (six times).

Test stimuli consisted of single Snodgrass and Vanderwart (1980) pictures. Each participant saw a total of 96 pictures, 48 old pictures (repeated from study) and 48 new pictures.

Procedure. Participants were instructed that on each trial, they would see a category name on the computer screen followed by an array of four pictures. They were told that one picture from the array would belong to the category, and that they were to name that picture aloud as quickly as possible. Because some of the category names might be considered ambiguous (e.g., household, signal), participants were given as much time as they liked (prior to the experiment) to study a sheet of paper listing the category names and their
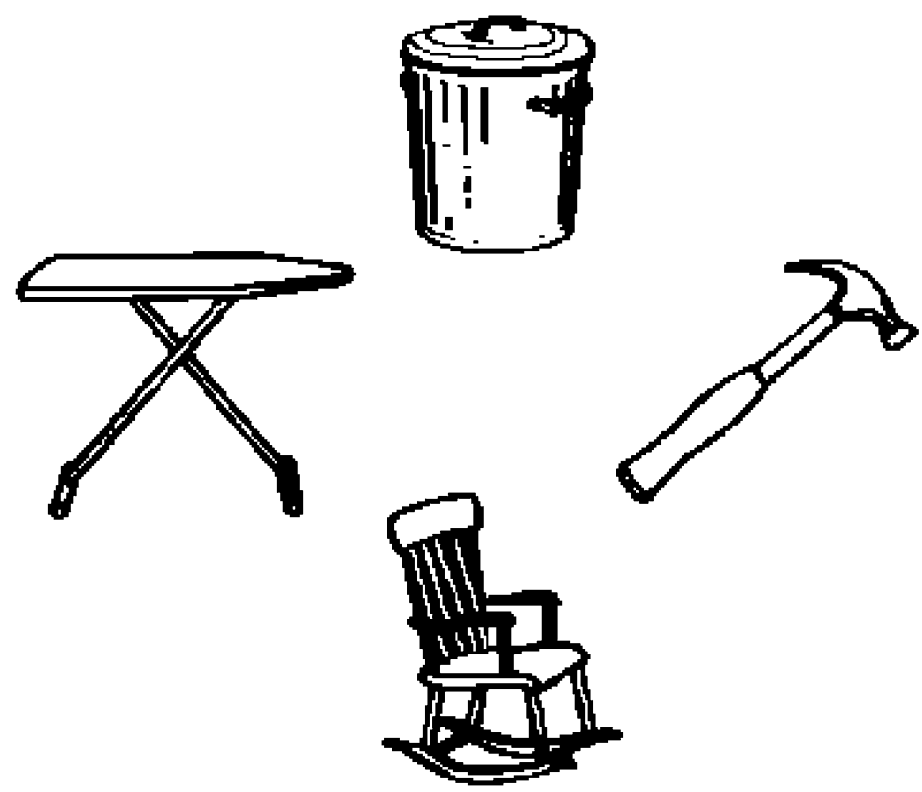

Figure 1. Example study array used in Experiment 1. Pictures were placed within $7^{\circ}$ of the center of the array assuming a viewing distance of $61 \mathrm{~cm}$ (viewing distance was not controlled). A category label (e.g., "tool") preceded the array. Participants were to name aloud the picture corresponding to the category ("hammer"). 
definitions. Trials were initiated by the participant (by pressing the space bar) and began with a category name for $1 \mathrm{sec}$, followed by a fixation point for $500 \mathrm{msec}$, and then the array of objects. The array remained until the participant gave an oral response. Including 2 practice trials, there were 50 trials during the study session. After the study session, participants were asked to return for a second session $1 \mathrm{~h}$ later; they were told nothing about the nature of the second task.

Participants who received the naming task in the second session saw single pictures and named each as quickly and as accurately as possible. Each trial was participant initiated and began with a fixation point for $500 \mathrm{msec}$, followed by a single picture that disappeared when the participant made a response. Including 3 practice trials, there were 99 trials.

For participants who received the recognition task in the second session, each trial began with a fixation point for $500 \mathrm{msec}$, followed by a picture. Participants pressed a "yes" key if the picture had appeared either as a target or as a nontarget at study, and a "no" key if it had not appeared. The instructions emphasized accuracy, not speed.

\section{Results}

Statistics reported in the text were computed using participants' mean response times (RTs) on the reasoning that systematic biases can occur when median RTs are compared across conditions with unequal numbers of trials (see Miller, 1988). Analyses were also conducted using median RTs and were qualitatively the same except where noted. In calculating participants' mean RTs for a condition, we removed those RTs with values less than $300 \mathrm{msec}$ (indicating a technical error) or greater than $2.5 S D$ over the participant's condition mean. Such trials amounted to $2.8 \%$ of the total.

Results are reported only for the test sessions. For participants in the naming condition, we omitted from the analysis those test trials in which participants gave an incorrect name (an alternative not listed by Snodgrass \& Vanderwart, 1980), a technical error occurred (e.g., microphone failures or spurious signals), or the corresponding study response was incorrect. Also omitted were trials with a different response than at study. An average of $11.4 \%$ of each participant's test trials were removed. For participants in the recognition condition, test stimuli corresponding to study trials on which participants made errors $(3.9 \%)$ were excluded from analysis.

Naming. RT to name individual pictures at test was the variable of interest. Unless otherwise stated, a significance level of .05 was used for all statistical tests. A oneway analysis of variance (ANOVA) with three levels (target, nontarget, and new) showed an effect of condition $\left[F(2,78)=34.5, M S_{\mathrm{e}}=6,092\right]$. Planned pairwise comparisons revealed that participants responded faster to targets $(M=881 \mathrm{msec}, S E=27)$ than to new items $(M=$ $1,017 \mathrm{msec}, S E=28)[F(1,78)=60.6, p<.01]$ and faster to targets than to nontargets $(M=993 \mathrm{msec}, S E=27)$ $[F(1,78)=41.1, p<.01]$. Naming times for nontargets and new items did not differ $[F(1,78)=1.9, p=.17]$.

Recognition. At test, participants responded "yes" to $95 \%$ of targets, $26 \%$ of nontargets, and $13 \%$ of new items. The hit rate for nontargets was reliably higher than the false alarm rate in the new condition $[t(19)=6.39, p<$ $.01]$. Hit rates for nontargets were also analyzed as a func- tion of the position of the targets in their study arrays. The effect of target position (top, bottom, left, right) on nontarget recognizability was not significant $(F<1)$. Further, hit rates for nontargets were not dependent on their position relative to the study target $\left[F(2,38)=1.98, M S_{\mathrm{e}}=\right.$ $346.7, p=.15]$.

\section{Discussion}

The facilitation for targets relative to new items demonstrated a basic priming effect. More interesting is that no priming was detected for nontargets. This result is consistent with the notion that the detection of priming at test may depend on the relevance of items to the study task. Only those pictures that were the focus of the study task were primed at test.

Results from the naming condition need not be explained in terms of task relevance, however, if participants did not even see the nontargets at study. Nontargets might not have been perceived if participants experienced a popout of the target that rendered search, and therefore perception of nontargets, unnecessary. There is evidence that target objects in similar "clockface" displays of common objects do not pop out even when the name of the target (as opposed to the category name) precedes the search (Biederman, Blickle, Teitelbaum, \& Klatsky, 1988). The long RTs $(1,400 \mathrm{msec})$ at study also argue against a popout effect. It seems reasonable to conclude that participants performed some type of search that would necessarily involve perception of some nontargets (one out of three on average, assuming a serial search)—and likely semantic access to their concepts.

In the recognition condition, the hit rate for targets in this experiment was typical of recognition following picture naming, which has been shown to be very good even after long delays (Cave \& Squire, 1992). The critical finding is that the hit rate for nontargets was reliably higher than the false alarm rate, even though participants were not instructed to memorize any portion of the array. This result suggests some explicit sensitivity to nontargets and shows that the lack of priming for nontargets was not caused by a failure to perceive any nontargets in the category search task; at least some nontargets were processed sufficiently to be recognized.

Experiment 1 suggests that viewing an array of pictures at study may not induce perceptual priming for pictures that are not the focus of the study task, although these pictures may be recognized explicitly. This pattern of results is consistent with the prediction that priming should be reduced or eliminated for entire stimuli that are perceived at study when they are not directly relevant to a study task. This interpretation, although consistent with TAP, is not the only potential explanation of the present data. Two primary alternatives must be addressed.

First, although the results of Experiment 1 suggest that at least some of the nontargets must be perceived, the data do not indicate exactly how many were perceived. Assuming that participants engaged in a serial, terminating search of the study arrays, it is virtually certain that only a subset of these pictures, perhaps half, were perceived. 
One would therefore expect the priming effect for nontargets to be lower than that for targets simply because some of the nontarget items appearing at test were not processed at study. Accounting for the results in terms of task relevance would derive strength from a study procedure in which all nontargets at study are seen. The following experiments address this concern.

Second, priming is confounded with a naming response in Experiment 1. The targets are the only pictures that participants name overtly at study, and also the only pictures that prime at test (for a similar manipulation involving words, see MacDonald \& MacLeod, 1998). The principle of TAP might therefore explain the data not in terms of differences in study-task relevance but in terms of overlap in response. Although there is no consensus on the relative contributions of perceptual processing, conceptual processing, and response production to priming in picture naming (Park \& Gabrieli, 1995), there is considerable evidence from studies of form changes (e.g., Park \& Gabrieli, 1995) and exemplar changes (e.g., Biederman \& Cooper, 1991a, 1991b; Cave et al., 1996) that suggests a strong perceptual component. Experiment 1, however, provides no direct evidence that response facilitation cannot account for the differences between targets and nontargets. This issue is addressed in Experiment 2.

\section{EXPERIMENT 2}

Experiment 1 failed to detect priming for stimuli that were not the focus of the study task. Others have observed similar target/nontarget differences and couched the results in terms of attention rather than task relevance-that is, priming is greatest for those items that receive the most attention (Stankiewicz, Hummel, \& Cooper, 1998). Because attention and task relevance are often correlated, it is difficult to tease apart their relative contributions to priming. Experiment 2 was designed to approach the issue by presenting participants with items that were displayed one at a time, foveally, without being task relevant.

In Experiment 2, participants were told that they were participating in a pupillary response experiment. Sets of stimuli were presented to "calibrate" a video camera monitoring their eyes. These stimuli were not relevant to a task, whereas others were presented under similar conditions but as part of a task. Picture naming was used at test to assess repetition priming in Experiments $2 \mathrm{~A}$ and 2B. Priming results were extended to another perceptually sensitive task in Experiment 2C. If priming is modulated by the study task, pictures shown within the context of a task should elicit priming, but stimuli presented outside the context of a task should not. If priming occurs automatically with perceptual processing, pictures shown both with and without a task should elicit similar levels of repetition priming.

\section{Experiment 2A}

The experiment consisted of four segments. Participants were told that we were interested in measuring their pupillary responses to pictures of objects, and that it would first be necessary to present a series of stimuli to "calibrate" the video monitoring. This cover story was introduced so that stimuli could be presented outside of the context of a task. This was followed by a series of pictures that were each covertly named (stimuli presented within the context of a task). After a delay there was a second camera "calibration" and then the picture-naming test, including items from each of the previous conditions as well as new items.

\section{Method}

Participants. Thirty-three participants similar to those described in Experiment 1 were tested. The data from 32 participants were analyzed. One participant was replaced because her mean RTs were at least $2.5 S D$ above those of the other participants.

Materials and Design. The experiment was conducted on a Macintosh IIci computer using PsyScope software (Cohen et al., 1993). A subset of the Snodgrass and Vanderwart (1980) line drawings were used as stimuli. The 200 pictures were subdivided into eight groups of 25 equated on name agreement (Snodgrass \& Vanderwart, 1980; range of mean name agreement: 0.47-0.48). Individual name agreement values ranged from 0 to 1.88 , with low values corresponding to high name agreement. These groups were rotated through conditions between participants in a Latin square. One group of stimuli (25) was used in each calibration phase, two groups (50) were used in the picture-naming study task, and all eight groups (200) were used in the test. Half of the test pictures were repeated from the study and calibration phases and half were new pictures.

Procedure. Participants were told that they would be taking part in an experiment designed to measure visual responsivity and that a video camera would be used to measure their pupillary responses to object identification. The experiment began with a camera calibration during which 25 pictures were shown for $300 \mathrm{msec}$ each, with approximately 550-msec blank interstimulus intervals (ISIs). Using a chinrest, participants were told merely to focus their eyes on the pictures while the video camera adjusted to their pupils during this initial calibration phase.

After the first calibration, participants were informed that a series of pictures of common objects would be presented in rapid succession, during which their pupillary responses would be recorded by the camera. The participants were told that their task was to silently name each picture as it appeared. The silent naming task consisted of 50 pictures, each presented for $300 \mathrm{msec}$, with an ISI of approximately $550 \mathrm{msec}$.

After a 15-min unmonitored delay, participants returned and were instructed that the camera would be calibrated again. The second calibration was identical to the first, except that 25 new pictures were presented. After the second calibration, participants were told that, to analyze the pupillary responses from the silent naming task, it was necessary to compare those results with a "known" baseline, such as pupillary responses to verbal identification of pictures. Participants were instructed to name aloud each picture as quickly and as accurately as possible. This test task consisted of all 200 pictures. Each picture was presented for $300 \mathrm{msec}$, followed by a blank intertrial interval (ITI) that lasted until the participant responded and the experimenter triggered the next trial.

\section{Results}

For each participant, mean and median test naming latencies were computed for pictures that had appeared in each calibration, for those from the silent naming task and for those from the new pictures at test. The averages of the mean latencies are shown in Table 1. Using the criteria described in Experiment 1, an average of $6.5 \%$ of trials were removed before analysis.

The mean naming latencies were subjected to a oneway ANOVA with four levels (first calibration, covertly 
Table 1

Measures of Priming for Test Responses in Experiment 2

\begin{tabular}{|c|c|c|c|c|c|c|}
\hline \multirow[b]{3}{*}{ Condition } & \multicolumn{6}{|c|}{ Experiment } \\
\hline & \multicolumn{2}{|c|}{$2 \mathrm{~A}$} & \multicolumn{2}{|c|}{$2 \mathrm{~B}$} & \multicolumn{2}{|c|}{$2 \mathrm{C}$} \\
\hline & $M$ & $S E$ & $M$ & $S E$ & Accuracy & $S E$ \\
\hline First calibration & 832 & 21 & 871 & 18 & 71 & 3 \\
\hline Study task & $798 *$ & 20 & $839 *$ & 18 & $77 *$ & 3 \\
\hline Second calibration & $811^{*}$ & 20 & $861^{*}$ & 19 & & \\
\hline New (baseline) & 849 & 20 & 885 & 18 & 69 & 3 \\
\hline
\end{tabular}

Note-Mean reaction times given in milliseconds; accuracy values represent percentages of correct test responses. The study task in Experiment 2A was silent naming, in Experiment $2 \mathrm{~B}$ was surface discrimination, and in Experiment $2 \mathrm{C}$ was a left/right facing judgment. $* p<.01$, difference from new (baseline).

named, second calibration, and new). This analysis showed an effect of condition $\left[F(3,93)=7.6, M S_{\mathrm{e}}=2,118\right]$. Planned pairwise comparisons revealed that participants responded faster to silently named items than to new items $[F(1,93)=19.8, p<.01]$. Further comparisons revealed that naming latencies for first calibration pictures differed from those for the silently named pictures $[F(1,93)=8.5$, $p<.01]$, but they did not differ from the naming latencies for the new pictures $[F(1,93)=2.4, p=.13]$. Pictures from the second calibration were named more quickly than new pictures $[F(1,93)=10.8, p<.01]$, but they did not differ from silently named pictures $[F(1,93)=1.3$, $p=.25]$. The difference between naming times for pictures that had appeared in the two calibration phases was marginal $[F(1,93)=3.1, p=.08]$ (although this difference was not significant in the analysis of median RTs, $p=.23$ ).

It is worth noting that RTs to new items in Experiment $2 \mathrm{~A}(849 \mathrm{msec})$ were considerably faster than RTs to new items in Experiment 1 (1,017 msec). Because stimulus sets overlap considerably, this difference is most likely attributable to having different participant samples in the two experiments.

\section{Discussion}

Participants named pictures repeated from the silent naming task more quickly than they named new pictures, demonstrating a basic priming effect. Despite the generally robust nature of repetition priming, this result was not a foregone conclusion. In the silent naming task, participants viewed 50 pictures in $42.5 \mathrm{sec}$ without making any overt responses. Priming under this type of processing demand has not been previously demonstrated. Although there have been previous demonstrations of priming following extremely brief stimulus exposures (mere exposure effects; Bar \& Biederman, 1996; Kunst-Wilson \& Zajonc, 1980; Seamon, Brody, \& Kauff, 1983), priming has not been tested under conditions of rapid serial presentation with brief ITIs as well as brief exposures. These results demonstrate the robust nature of repetition priming when stimuli are perceived to be relevant to task performance.

Pictures repeated from the first calibration were shown under the same exposure conditions, but without the instruction to process each individual picture. However, priming was detected for the silently named pictures but not for the first calibration pictures. Both conditions preceded the picture-naming test by approximately $15 \mathrm{~min}$, and both conditions allowed $850 \mathrm{msec}$ of processing time for each picture. The only difference between these conditions was the instructions given to the participants before each condition.

It remains possible that priming was reduced for pictures from the first calibration phase because of a difference in the responses to the pictures at study. The silent naming phase required a response (albeit covert) and the calibration phase did not. However, Brown, Neblett, Jones, and Mitchell (1991) demonstrated no differences in priming effects between covert naming and passive viewing. Although priming under passive-viewing conditions does not appear consistent with the proposed study-task relevance account of priming, perhaps the experimental setting itself can provide a "task" for these stimuli. Cognitive psychology studies, almost by definition, require participants to perform tasks with stimuli. Little chance is afforded for participants to conclude that some of the stimuli are irrelevant. Even passive-viewing conditions offer no realistic cover to suggest that the stimuli being shown are simply superfluous. With the expectations that participants bring to an experiment, they may treat any individually presented object as the focus of a task. Thus, in a laboratory setting, the researcher must provide a rationale (such as the "camera calibration" cover story used in the present study) to assure participants that presented stimuli are not the focus of a task. Additionally, when participants were asked to report what they were doing during the calibrations, over half of them reported that they were silently naming the pictures. Because picture naming is such a simple and natural response (e.g., Potter \& Faulconer, 1975), it is not surprising that many participants were silently naming the pictures during the first calibration. This further strengthens the argument that the only difference between these two conditions was the perception of the stimuli as having relevance for the performance of a task.

Some priming was detected for pictures seen in the second calibration phase. This might be attributed to the lack of delay between this phase and the test, or it might have been due to participants maintaining the study-task instruction into the second calibration. Although strong prim- 
ing effects in picture naming are known to persist over long delays (e.g., weeks; Cave, 1997; Mitchell \& Brown, 1988), the forgetting curve for picture naming in the minutes immediately following study is not known (see Sloman, Hayman, Ohta, Law, \& Tulving, 1988, for a discussion of rapid forgetting in primed word-fragment completion). Given the generally robust nature of priming in this paradigm, we speculate that the difference between the calibration conditions is more likely attributable to instruction or perceived relevance of different conditions to the performance of a task. In a laboratory environment it may be difficult for participants to "turn off" a task once it has been introduced.

\section{Experiment 2B}

In Experiment 2A, participants may have performed differently on the items from the first calibration and the items from the silent naming task because of different degrees of processing overlap between each of these conditions and the picture-naming test. The calibrations required only that the participants perceive the stimuli. The silent naming task required perception of the stimuli as well as access to the names of the stimuli. Because picturenaming tests require perception as well as lexical access, it remains possible that the source of the facilitation for pictures repeated from the silent naming task was an overlap of processing associated with lexical access (Lachman \& Lachman, 1980, but see Biederman \& Cooper, 1991b).

In the study phase of Experiment 2B, participants were asked to decide whether the pictured objects were composed of primarily flat or curved surfaces. Thus, pictures in the study condition were presented in the context of a task that did not require access to the names of the stimuli, yet still tapped into the perceptual qualities of the stimuli. In addition, the study and test tasks used in this experiment required different responses to ensure that priming effects were the result of stimulus processing facilitation rather than response facilitation.

\section{Method}

Participants. Thirty-two participants similar to those described in Experiment 1 were tested.

Materials and Design. The materials and design were identical to those used in Experiment 2A.

Procedure. Procedures were identical to those of Experiment 2A with the exception of the instructions for the study phase of the experiment. After the first calibration, participants were told that a series of pictures of common objects would be presented in rapid succession, during which their pupillary responses would be recorded by the camera. Participants were instructed that their task was to determine whether each picture represented an object composed of predominantly flat surfaces or curved surfaces. Examples of objects with mostly flat surfaces (computer, archery target) or curved surfaces (panda, beaker) were given. To promote an analysis of the overall object rather than the two-dimensional characteristics of the picture, participants were told to base their decisions on the surfaces of the object rather than the lines in the picture of the object, because a predominantly flat object could be depicted with curved lines, or vice versa (e.g., a coin is predominantly flat, although the lines used to represent a picture of the face of a coin are mostly curved). The participants were warned that the pictures would be presented at a fixed rapid rate, and thus they would have only a limited time to respond to each picture. As in Experiment 2A, pictures were presented for $300 \mathrm{msec}$, with an ISI of $550 \mathrm{msec}$. Participants were instructed to press one key for objects with flat surfaces and another key for objects with curved surfaces. Immediately prior to the actual study phase, participants took part in a short practice test of 30 items to acclimate them to the task. The items from the practice phase were new pictures chosen from the set of line drawings by Snodgrass and Vanderwart (1980). These pictures did not appear again in the experiment.

Following a 15-min delay, half of the participants took part in a picture-naming test identical to that used in Experiment 2A. The other half of the participants were asked to name each picture as quickly as possible and then to recognize whether they had previously seen each picture at any time in the experiment. For the naming-plusrecognition trials, a 1-sec delay was imposed following the participant's naming response. Then the words "new or old" appeared on the screen. Participants pressed the "old" key if the picture had appeared at any time previously in the experiment (in study or calibration phases) and "new" otherwise. The instructions for the recognition task emphasized accuracy, not speed.

\section{Results}

Naming. As in the previous experiments, only the naming latencies for pictures named at test were analyzed.Using the same criteria from Experiment 1,5\% of the trials were excluded prior to the analysis. For each participant, mean and median naming latencies were computed for pictures that had appeared in each calibration, the surface discrimination study task, and for the new pictures at test. Results based on mean latencies are reported. Results based on median latencies did not differ except where noted. The averages of the mean latencies are shown in Table 1.

The mean naming latencies were subjected to a $4 \times 2$ mixed ANOVA with a within-subjects factor of study condition (first calibration, surface discrimination, second calibration, and new) and a between-subjects factor of test type (naming only vs. naming plus recognition). This analysis showed an effect of study condition $[F(3,90)=9.2$, $\left.M S_{\mathrm{e}}=1,292\right]$. Planned pairwise comparisons revealed that participants responded faster to items repeated from the surface discriminationtask than to new items $[F(1,90)=$ $25.9, p<.01]$. Further comparisons revealed that the first calibration items differed from the items from the surface discrimination task $[F(1,90)=12.9, p<.01]$, but they did not differ from new items $[F(1,90)=2.3, p=.14]$. Items from the second calibration differed from new items $[F(1,90)=7.1, p<.01]$, as well as from surface discrimination study items $[F(1,90)=5.9, p<.05]$. Examination of results based on medians revealed that items repeated from the second calibration did not differ from items repeated from the surface discrimination task. Comparisons between first calibration items and second calibration items revealed no difference in naming latencies $[F(1,90)=1.52, p=.22]$.

The analysis also revealed that RTs for participants in the naming-only condition ( $851 \mathrm{msec}$ ) did not differ from those of participants in the naming-plus-recognition condition ( $877 \mathrm{msec}, F<1)$. In addition, there was no interaction between experimental condition and test type $[F(3,90)=1.2, p=.32]$. 
Recognition. The 16 participants in the naming-plusrecognition condition responded "old" to $70 \%$ of the study items, $55 \%$ of the first calibration items, $56 \%$ of the second calibration items, and $24 \%$ of the new items. The hit rate for items from the study condition was above the false alarm rate for new items $[t(45)=10.0, p<.01]$. The hit rate for each calibration condition was reliably higher than the false alarm rate to the new items $[t(45)=6.7, p<.01$, for the first calibration items and $t(45)=7.1, p<.01$, for the second calibration items], but less than the hit rate for study items $[t(45)=3.3, p<.01$, for the first calibration items and $t(45)=2.9, p<.01$, for the second calibration items].

Independence of naming and recognition. An independence analysis of the items from the naming-plusrecognition condition was conducted to determine whether performance on the naming task was contingent on performance on the recognition task. For each participant, RTs for items in the picture-naming test were analyzed according to whether that item received an "old" or "new" response in the recognition test. For 3 participants, data from a condition were excluded prior to analysis because the participant made four or fewer errors in recognition in that condition. This analysis showed that participants did not respond significantly faster to items receiving an "old" response $(882 \mathrm{msec})$ than to items receiving a "new" response $(896 \mathrm{msec})[t(60)=1.0, p=.33]$. Independence between naming and recognition was also analyzed separately for items in each condition: first calibration (called "old" = $878 \mathrm{msec}$, called "new" = $894 \mathrm{msec}$ ), surface discrimination study phase (called "old" $=859 \mathrm{msec}$, called "new" = $881 \mathrm{msec}$ ), second calibration (called "old" = $892 \mathrm{msec}$, called "new" = $916 \mathrm{msec}$ ), and new items (called "old" = $889 \mathrm{msec}$, called "new" = $900 \mathrm{msec}$ ). Independence between naming and recognition performance was found for all conditions (in each case, $p>.25$ ).

\section{Discussion}

As in Experiment 2A, participants named pictures repeated from study more rapidly than new pictures, demonstrating a basic priming effect. Likewise, priming was not detected for pictures repeated from the first calibration. Recognition performance for these items clearly indicates that the pictures from the calibrations were perceived. These results are consistent with the notion that the occurrence of priming is contingent upon a link between the perception at study and performance of a task. Priming was detected despite different task requirements at study and test, suggesting that the facilitation at test was not a by-product of simple response overlap.

The difference between study and first calibration pictures occurred even though both sets of stimuli were presented under identical viewing conditions: Both preceded the test by approximately $15 \mathrm{~min}$, and both allowed $850 \mathrm{msec}$ of processing time for each picture. The only difference between the two conditions was the instructions given prior to each condition.
The hit rate for recognizing pictures that appeared in the calibrations was reliably higher than the false alarm rate for new items. This confirms that participants were perceiving the calibration pictures, despite showing no priming for the pictures from the first calibration. As in Experiment 1 , this is another instance of a dissociation between implicit and explicit memory in the opposite direction than is typically reported. This study suggests that stimuli that are not perceived as relevant to the solution of a task and, therefore, may not produce a modification that can be detected as priming, are still available to explicit memory.

As in Experiment 2A, pictures repeated from the second calibration did show priming at test. We speculate that this result is due to a task carryover effect from the surface discrimination task. Participants found the study task used in this experiment to be very difficult. When they returned for the second calibration, participants were aware that another task would follow, but they were not informed of the nature of the test task until after the second calibration. When questioned after the experiment, many participants reported that they expected the second calibration to be followed by another surface discrimination task, and most of the participants reported that they were identifying surfaces during the second calibration. Thus, participants may have been treating the second calibration as a "practice session" for the upcoming test. As discussed previously, however, the possibility remains that difference between the calibration conditions is caused by rapid forgetting after study.

Priming was demonstrated for pictures repeated from the surface discrimination task despite the fact that this task does not require lexical access. Neither the calibrations nor the study task required that the participant access the names of the stimuli, although these conditions required that the participant perceive each stimulus. Only in the study phase, however, were the stimuli relevant to the solution of a task. The picture-naming test required that the participant perceive the stimuli in addition to accessing the names of the stimuli. It seems likely, therefore, that priming effects in this experiment were due to perceptual overlap between study and test rather than lexical overlap (e.g., Biederman \& Cooper, 1992). The finding that the pictures from the first calibration showed no priming at test, however, indicates that perceptual processing alone is not sufficient to induce priming. Because the only difference between the stimuli presented in the calibrations and the study phase was the instructions given for each condition, these results suggest that priming may be mediated by the relevance of the stimuli to the solution of a task.

Given that picture naming is a relatively easy and natural task (Mitchell \& Brown, 1988), one might argue that lexical access occurs automatically when participants are presented with pictures of common objects. After all, it is difficult to imagine that a participant could see a picture of a chair and not recognize it almost immediately as a chair. However, if it is the case that lexical access occurs auto- 
matically when pictures of common objects are presented, then lexical access must be occurring in the calibrations as well as in the study phase. Thus, the notion that priming occurs due to lexical access cannot account for differential priming between the first calibration and the study phase.

\section{Experiment 2C}

The previous experiments provide evidence for priming that is modulated by task demands when picture naming is used as the test task. Picture naming has been repeatedly demonstrated to be sensitive to perceptual qualities of stimuli, but can evidence for task-modulated priming be exhibited in other perceptually sensitive tasks? It might be argued that modifications that lead to priming occur for all stimuli that are perceived, but that greater levels of priming occur for stimuli that are processed during a more perceptually demanding activity. Because picture naming is a relatively easy task, perhaps it is not sensitive enough to perceptual qualities to tap into any modifications that may occur when stimuli are presented outside of the context of a task. In other words, perhaps we failed to detect priming for the pictures presented in the first calibration phase because picture naming is just not a sensitive enough test to pick up very small effects (although under a strict "perception is enough" model, the priming effects for the stimuli presented outside the context of a task should not be much, if any, smaller than for stimuli presented within the context of a task). If in fact perceptual modifications occur for all perceived stimuli, but these modifications are not detectable in a perceptually easy task such as picture naming, using a more perceptually challenging test task might tap into these modifications in a way that picture naming does not.

In Experiment 2C, novel stimuli were used to ensure that the processing that occurred during each condition was perceptual in nature rather than lexical. Thus, naming overlap between study and test could not account for priming effects. The study and test tasks used in this experiment were previously used by Schacter et al. (1990). Line drawings of three-dimensional structures were presented. The study task was a left/right facing judgment, and the test task was to decide whether each object represented a possible or impossible three-dimensional structure. Although the study and test tasks differed from each other, both tasks presumably require perceptual processing. Additionally, test stimuli were presented very briefly to make the test more perceptually challenging.

\section{Method}

Participants. Twenty-four participants similar to those described in Experiment 1 were tested.

Materials and Design. The apparatus was identical to that of the previous experiments. The stimuli used in this experiment were 144 line drawings of figures that were structurally possible or impossible in three dimensions. Half of these stimuli were used by Schacter et al. (1990), and the other 72 were drawn from other sources. Half of the stimuli pictured possible objects (objects that could exist in three-dimensional space), and the other half pictured impossible objects (objects with violations of form such that they could not exist
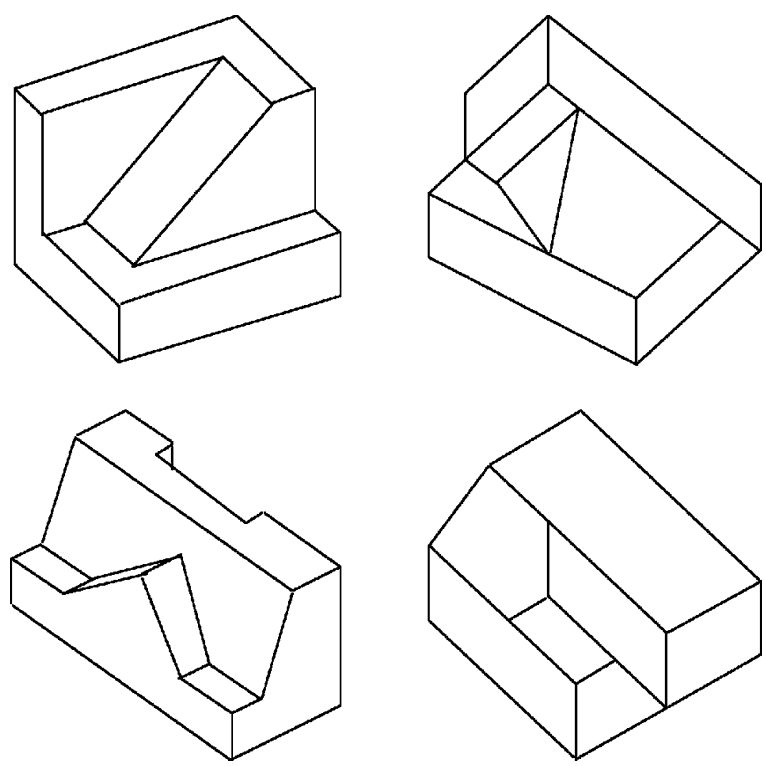

Figure 2. Examples of possible and impossible figures used in Experiment 2C. Objects on the left represent possible figures (objects that could exist in three-dimensional space), and objects on the right represent impossible figures (objects with violations of form such that they could not exist in three-dimensional space). The pictured stimuli were taken from a stimulus set used by Schacter et al. (1990).

in three-dimensional space). Examples of the stimuli used in this experiment are shown in Figure 2. The 144 pictures were subdivided into three groups of 48 pictures, with each group containing equal numbers of possible and impossible figures. Prior to this study, normative data were gathered for these stimuli. Participants in the normative study were asked to rate, on a scale of $1-7$, the complexity and the impossibility of each item in the stimulus set. The three groups of stimuli used in this study were matched according to the ratings gathered in the normative study (range of mean complexity: 4.56-4.63; range of mean impossibility: 3.83-4.00).

The design used in this experiment was similar to that used in the previous experiments with the exception that the second calibration was excluded. This exclusion was made because little information related to the hypothesis being tested was garnered from the second calibration in previous experiments, and the number of available stimuli was limited. One group of stimuli was used in the calibration phase, and a different group was used in the study phase. All three groups were used in the test phase. Thus, one third of the test pictures were repeated from the calibration, one third were repeated from the study phase, and one third were new pictures. These groups were rotated through conditions between participants in such a way that every group appeared equally often in each condition.

Procedure. The procedures used in this experiment were similar to those from Experiments 2A and 2B with the following exceptions. After the initial camera calibration, participants were instructed that they would be seeing pictures of three-dimensional objects. The participants were told that their task was to judge whether each object was facing to the left or to the right. The participants were warned that the pictures would be presented at a fixed rapid rate, and thus they would have only a limited time to respond to each picture. Participants pressed one key for objects they determined to be left facing and another key for objects they determined to be right facing.

A delay of 5 min was imposed between the study phase and the test phase. During the delay, participant activity was not controlled 
or monitored. When participants returned for the test phase, they were instructed that a series of line drawings of three-dimensional structures would be presented, and that their task was to determine whether each drawing depicted a structurally possible (could exist in the real world) or impossible object. Participants were given examples of possible and impossible objects and were warned that each picture would appear very briefly. Because of the dearth of available stimuli, no practice trials were given.

Each trial was initiated when the participant pressed a key. An asterisk appeared for $750 \mathrm{msec}$ at a central location where the object would appear. Each object was presented for $100 \mathrm{msec}$, followed by a pattern mask that was present for $300 \mathrm{msec}$. The mask consisted of a complex pattern of lines designed to hide any afterimage of the stimulus. The next screen instructed participants to indicate their response by pressing one key if the object was possible and another key if the object was impossible. Participants were asked to emphasize response accuracy rather than speed.

\section{Results}

The proportion of correct responses for items presented in the object decision test were of primary interest. In this paradigm, priming is reflected by increased response accuracy for repeated items relative to new items. All trials were analyzed for each participant. The percentage of correct responses was computed for pictures in each condition of the object decision test: repeated from the calibration, repeated from the left/right facing study task, and new items. Separate percentages were calculated for possible and impossible figures. The averages of the percentages for possible figures are shown in Table 1 .

The percentages of correct responses to possible figures were subjected to a one-way ANOVA with three levels (calibration, study, and new). The analysis showed an effect of condition $\left[F(2,46)=14.1, M S_{\mathrm{e}}=0.3\right]$. Planned pairwise comparisons revealed that participants responded more accurately to items repeated from the study phase than to new items $[F(1,46)=26.5, p<.01]$. Further comparisons revealed that accuracy for items repeated from the calibration differed from accuracy for the study items $[F(1,46)=13.6, p<.01]$, but not from accuracy for new items $[F(1,46)=2.1, p=.15]$. Consistent with previous findings by Schacter et al. (1990), an analysis of the percentages of correct responses to impossible figures revealed no effect of condition $(F<1)$.

\section{Discussion}

Participants responded more accurately to pictures repeated from the left/right facing judgment study task than to new items, demonstrating a basic priming effect. The effect was detected despite the fact that the 48 items in the study task were all presented in under $41 \mathrm{sec}$. The size of the priming effect found in this experiment was substantially smaller than that found by Schacter et al. (1990), but the small size of the effect was likely due to the demanding conditions under which the stimuli were presented at study. These results add to the evidence that repetition priming is very robust when stimuli are presented in the context of a task.

Participants showed priming for pictures repeated from the left/right facing judgment task but not for pictures re- peated from the calibration, although both were shown under the same exposure conditions. The only difference between the calibration and the study conditions was the instructions given prior to each condition. This experiment furthers the argument that priming is contingent upon the perceived importance of the stimuli to the performance of a task.

The stimuli used in this experiment were novel. Because participants had never encountered these stimuli prior to this experiment, priming effects cannot have been due to modifications in lexical or semantic information about the stimuli. Additionally, priming effects cannot have been a by-product of pure response facilitation, because different responses were required at study and test. Thus, priming effects must have been due to modifications brought about by the perceptual processing of the stimuli (Schacter et al., 1990; but see Ratcliff \& McKoon, 1995).

In the object decision test task, stimuli were presented for only $100 \mathrm{msec}$ each. Such brief, masked presentations should have increased the perceptual demands of the test task, making the test more sensitive to modifications in perceptual processing that may have occurred previously in the experiment. Despite the increased perceptual sensitivity of the test, items repeated from the calibration did not show significant priming. This suggests that no modifications of processing that would later be detectable as priming occurred for the stimuli presented in the calibration. The results of this experiment suggest that modifications in perceptual processing may not occur for every stimulus that is perceived; rather, modifications in processing are modulated by whether the stimulus is relevant to the performance of some task.

\section{GENERAL DISCUSSION}

Consistent findings emerged across experiments with a variety of encoding conditions, test tasks, and stimuli. In all cases, stimuli that were the focus of a study task elicited significant priming, whereas stimuli that had not been the focus of a study task did not elicit priming. In combination with the results of Oliphant (1983) and others, these results suggest that the strength of repetition priming may be modulated by the relevance of a stimulus to the completion of the task in which it was initially encountered.

Major alternative explanations of the results of Experiment 1-namely, that the difference between targets and nontargets reflects facilitation in the naming response or increased visual attention-do not seem to account for the entire set of results. Similar data patterns occurred when nontarget items received the same amount of exposure (Experiment 2), when the responses at study and test did not overlap (Experiment 2B ), and even when the test task did not involve naming at all (Experiment 2C). Furthermore, as demonstrated in Experiment 2, not all stimuli that are visually attended are important to the solution of a task, and task-relevant stimuli showed significant facilitation relative to stimuli that were visually attended outside the context of a task. A more plausible conclusion attributes the differ- 
ences in priming to the influence of the study-task context in defining which items are and are not important.

This modulation of the priming effect is consistent with TAP (e.g., Blaxton, 1989; Roediger et al., 1989), which attributes variation in priming to corresponding variation in the extent of processing overlap between the study and test tasks. If processing is minimized because a stimulus is not critical to task performance, one could expect that there will be less chance of creating an overlapping test task. Lest the claim seem trivial, it is not our claim that nontargets and first calibration items were not processed at all at study. The finding of significant explicit memory for these items argues against this possibility. Further, passive-viewing conditions similar to those of the calibration conditions in Experiment 2 have previously produced robust priming in picture naming (Brown et al., 1991). Thus, the absence of priming does not seem to suggest the total absence of processing for these items at study.

The concept of study-task-sensitive priming also strengthens the TAP approach by elaborating why study/ test overlap is so important for priming. According to this view, the information that will appear in the representation that supports priming is determined by the demands of the study task. This explains the flexibility of priming observed in previous studies: Priming is sensitive to size changes following study tasks that emphasize object size (Srinivas, 1996) and insensitive to size changes following study tasks that focus only on object structure (Schacter et al., 1990). Nonoverlapping test tasks in this framework are those tasks that attempt to "tap" information that is not there. The data from these experiments suggest that the flexibility of priming may extend beyond the selection of particular object features and may influence the strength of the representation of the object itself. If the demands of the study task define only a subset of stimuli as important, the perception of other, less important, stimuli within that task may fail to elicit robust priming.

Numerous findings in repetition priming research are consistent with this general framework. Because perceptual repetition priming is elicited anytime a stimulus is the perceptual focus within a task, depth of processing should not affect perceptual priming (Jacoby \& Dallas, 1981). A stimulus that is the focus of any task, deep or shallow, should modify processing in a way that can be tapped by a perceptual test (Weldon \& Roediger, 1987). As discussed earlier, study-task sensitivity also explains the findings of robust priming for objects across changes in size, color, left/right reflection, and modality (Biederman \& Cooper, 1992; Cave, 1997; Cave et al., 1996; Cooper et al., 1992; Easton, Srinivas, \& Greene, 1997) and begins to draw together the seemingly disparate results on the specificity of priming for words (Graf \& Ryan, 1990). Although these interpretations follow rather than precede the results, the present task-sensitive account of priming is not without predictive value. Focusing on task requirements may ultimately enable researchers to make more precise predictions about patterns of priming by applying theories of the study task (e.g., object or word identification) in which stimuli are perceived. This account thus offers a route to prediction via an understanding of the domain in which priming is measured.

The results of this study suggest, but do not guarantee, that priming is eliminated for task-irrelevant items. Across priming tasks, participants consistently responded numerically, if not significantly, faster or more accurately to task-irrelevant than to new items-raising the possibility that the test tasks simply failed to detect the priming effect for task-irrelevant items. Although these experiments used conventional numbers of participants, and although the "effect" observed for nontargets amounted to less than $2 \%$ facilitation (smaller than any reported perceptual priming effect), the null effects reported here should be interpreted cautiously until replicated in a number of paradigms with substantial power. It is worth noting, however, that if priming proves to be nonexistent for these stimuli, the result would require an extension of TAP, for it would reveal priming to be dependent not only on processing overlap between study and test tasks, but also on the utility of a stimulus to the performance of the study task in the first place.

The concept of study-task-sensitive priming is attractive because it begins to approach the perplexing issue of the function of repetition priming. Clearly, much of what we perceive daily is of no special relevance. Individual cars, trees, and light poles blend to form a scene that the visual system parses readily and completely, but this scene contains only a few objects that are of any concern at any given time. Why should this information not be facilitated? If priming were to occur with every perceptual experience, the functional potential for priming would seem to be diminished; no stimulus in the environment would receive greater processing facilitation than any other. Further, given the very long duration of priming and observed diminishing returns in facilitation with multiple exposures (Logan, 1990), perception for objects that are at all familiar would quickly reach an irreducible minimum, because they would be repeatedly encountered during the 48-week span that priming is known to last (Cave, 1997).

Although priming could simply provide incremental facilitation as described in Logan's (1990) model, priming would seem to have greater potential utility if used as a means of differentiating stimuli based on relevance to the task at hand, especially given that modifying processing for every leaf, bush, or piece of trash would place a burden on implicit memory processes that would far outweigh the usefulness of the result. If priming is more selective, we may think of it as facilitating processing of items and features that are important now-and likely important in the future. Such flexible processing facilitation would seem highly adaptive.

\section{REFERENCES}

Bar, M., \& Biederman, I. (1996, April). Subliminal visual priming. Poster presented at the annual meeting of the Association for Research in Vision and Ophthalmology, Sarasota, FL.

Bartram, D. J. (1974). The role of visual and semantic codes in object naming. Cognitive Psychology, 6, 325-356.

Biederman, I., Blickle, T. W., Teitelbaum, R. C., \& Klatsky, G. J. 
(1988). Object search in nonscene displays. Journal of Experimental Psychology: Learning, Memory, \& Cognition, 14, 456-467.

Biederman, I., \& Cooper, E. E. (1991a). Evidence for complete translational and reflectional invariance in visual object priming. Perception, 20, 585-593.

Biederman, I., \& Cooper, E. E. (1991b). Priming contour-deleted images: Evidence for intermediate representations in visual object recognition. Cognitive Psychology, 23, 393-419.

Biederman, I., \& Cooper, E. E. (1992). Size invariance in visual object priming. Journal of Experimental Psychology: Human Perception \& Performance, 18, 121-133.

Biederman, I., \& Gerhardstein, P. C. (1993). Recognizing depth-rotated objects: Evidence and conditions for three-dimensional viewpoint invariance. Journal of Experimental Psychology: Human Perception \& Performance, 19, 1162-1182.

BlaXton, T. A. (1989). Investigating dissociations among memory measures: Support for a transfer-appropriate processing framework. Journal of Experimental Psychology: Learning, Memory, \& Cognition, 15, 657-668.

BRooks, J. O. (1985). Pictorial stimuli for the Apple Macintosh computer. Behavior Research Methods, Instruments, \& Computers, 17, 409-410.

Brown, A. S., Neblett, D. R., Jones, T. C., \& Mitchell, D. B. (1991). Transfer of processing in repetition priming: Some inappropriate findings. Journal of Experimental Psychology: Learning, Memory, \& Cognition, 17, 514-525.

Bruce, V., Carson, D., Burton, A. M., \& Ellis, A. W. (2000) Perceptual priming is not a necessary consequence of semantic classification of pictures. Quarterly Journal of Experimental Psychology, 53A, 289-323.

CAve, C. B. (1997). Very long-lasting priming in picture naming. Psychological Science, , 8, 322-325.

CAve, C. B., Bost, P. R, \& Совв, R. E. (1996). Effects of color and pattern on implicit and explicit picture memory. Journal of Experimental Psychology: Learning, Memory, \& Cognition, 22, 639-653.

CAVE, C. B., \& SQuire, L. R. (1992). Intact and long-lasting repetition priming in amnesia. Journal of Experimental Psychology: Learning, Memory, \& Cognition, 18, 509-520.

Cohen, J. D., MacWhinney, B., Flatt, M., \& Provost, J. (1993). PsyScope: An interactive graphic system for designing and controlling experiments in the psychology laboratory using Macintosh computers. Behavioral Research Methods, Instruments, \& Computers, $\mathbf{2 5}$, 257-271.

Cooper, L. A., Schacter, D. L., Ballesteros, S., \& Moore, C. (1992). Priming and recognition of transformed three-dimensional objects: Effects of size and reflection. Journal of Experimental Psychology: Learning, Memory, \& Cognition, 18, 43-57.

Easton, R. D., Srinivas, K., \& Greene, A. J. (1997). Do vision and haptics share common representations? Implicit and explicit memory within and between modalities. Journal of Experimental Psychology: Learning, Memory, \& Cognition, 23, 153-163.

Gabrieli, J. D. E., Vaidya, C. J., Stone, M., Francis, W. S., ThompsonSchill, S. L., Fleischman, D. A., Tinklenberg, J. R., Yesavage, J. A., \& WiLson, R. S. (1999). Convergent behavioral and neuropsychological evidence for a distinction between identification and production forms of repetition priming. Journal of Experimental Psychology: General, 128, 479-498.

GRAF, P., \& RyAN, L. (1990). Transfer-appropriate processing for implicit and explicit memory. Journal of Experimental Psychology: Learning, Memory, \& Cognition, 16, 978-992.

Horton, K. D., Wilson, D. E., \& Evans, M. (2001). Measuring automatic retrieval. Journal of Experimental Psychology: Learning, Memory, \& Cognition, 27, 958-966.

Humphreys, G. W., \& RidDoch, M. J. (1987). Normal and pathological processes in visual object constancy. In G. W. Humphreys \& M. J. Riddoch (Eds.), Visual object processing: A cognitive neuropsychological approach (pp. 43-105). Hillsdale, NJ: Erlbaum.

JACOBY, L. L., \& DALlas, M. (1981). On the relationship between autobiographical memory and perceptual learning. Journal of Experimental Psychology: General, 110, 306-340.

Johnson, D. N. (2000). Task demands and representation in long-term repetition priming. Memory \& Cognition, 28, 1303-1309.
Kroll, J. F., \& Potter, M. C. (1984). Recognizing words, pictures, and concepts: A comparison of lexical, object, and reality decisions. Journal of Verbal Learning \& Verbal Behavior, 23, 39-66.

Kunst-Wilson, W. R., \& ZaJonc, R. B. (1980). Affective discrimination of stimuli that cannot be recognized. Science, 207, 557-558.

Lachman, R, \& Lachman, J. L. (1980). Picture naming: Retrieval and activation of long-term memory. In L. W. Poon (Ed.), New directions in memory and aging: Proceedings of the George A. Talland Memorial Conference (pp. 313-343). Hillsdale, NJ: Erlbaum.

LeVy, B. A., \& KirSner, K. (1989). Reprocessing text: Indirect measures of word and message level processes. Journal of Experimental Psychology: Learning, Memory, \& Cognition, 15, 407-417.

LogAN, G. D. (1990). Repetition priming and automaticity: Common underlying mechanisms? Cognitive Psychology, 22, 1-35.

MacDonald, P. A., \& MacLeod, C. M. (1998). The influence of attention at encoding on direct and indirect remembering. Acta Psychologica, 98, 291-310.

MacLeod, C. M. (1989). Word context during initial exposure influences degree of priming in word fragment completion. Journal of $E x$ perimental Psychology: Learning, Memory, \& Cognition, 15, 398-406.

Miller, J. (1988). A warning about median reaction time. Journal of Experimental Psychology: Human Perception \& Performance, 14, 539-543.

Mitchell, D. B., \& BRown, A. S. (1988). Persistent repetition priming in picture naming and its dissociation from recognition memory. Journal of Experimental Psychology: Learning, Memory, \& Cognition, 14, 213-222.

Oliphant, G. W. (1983). Repetition and recency effects in word recognition. Australian Journal of Psychology, 35, 393-403.

Park, S. M., \& Gabrieli, J. D. E. (1995). Perceptual and non-perceptual components of implicit memory for pictures. Journal of Experimental Psychology: Learning, Memory, \& Cognition, 21, 1583-1594.

Perruchet, P., \& Baveux, P. (1989). Correlational analyses of explicit and implicit memory performance. Memory \& Cognition, 17, 77-89.

Potter, M. C., \& Faulconer, B. A. (1975). Time to understand pictures and words. Nature, 253, 437-438.

Ratcliff, R, \& McKoon, G. (1995). Bias in the priming of object decisions. Journal of Experimental Psychology: Learning, Memory, \& Cognition, 21, 754-767.

RichaRdSON-KLAVEHN, A., \& BJoRK, R. A. (1988). Measures of memory. Annual Review of Psychology, 39, 475-543.

Riddoch, M. J., \& Humphreys, G. W. (1987). Picture naming. In G. W. Humphreys \& M. J. Riddoch (Eds.), Visual object processing: A cognitive neuropsychological approach (pp. 107-143). Hillsdale, NJ: Erlbaum.

Roediger, H. L., III, \& Blaxton, T. A. (1987). Effects of varying modality, surface features, and retention interval on priming in wordfragment completion. Memory \& Cognition, 15, 379-388.

Roediger, H. L., III, Weldon, M. S., \& Challis, B. H. (1989). Explaining dissociations between implicit and explicit measures of retention: A processing account. In H. L. Roediger III \& F. I. M. Craik (Eds.), Varieties of memory and consciousness: Essays in honour of Endel Tulving (pp. 3-41). Hillsdale, NJ: Erlbaum.

Schacter, D. L. (1992). Priming and multiple memory systems: Perceptual mechanisms of implicit memory. Journal of Cognitive Neuroscience, 4, 244-256.

Schacter, D. L., Cooper, L. A., \& Delaney, S. M. (1990). Implicit memory for unfamiliar objects depends on access to structural descriptions. Journal of Experimental Psychology: General, 119, 5-24.

SeAmon, J. G., Brody, N., \& Kauff, D. M. (1983). Affective discrimination of stimuli that are not recognized: Effects of shadowing, masking, and cerebral laterality. Journal of Experimental Psychology: Learning, Memory, \& Cognition, 9, 544-555.

Sloman, S. A., Hayman, C. A. G., Ohta, N., Law, J., \& Tulving, E. (1988). Forgetting in primed fragment completion. Journal of Experimental Psychology: Learning, Memory, \& Cognition, 14, 223-239.

SNODGRASS, J. G., \& VANDERWART, M. (1980). A standardized set of 260 pictures: Norms for name agreement, image agreement, familiarity, and visual complexity. Journal of Experimental Psychology: Human Learning \& Memory, 6, 174-215.

Squire, L. R., Zola-Morgan, S., Cave, C. B., Haist, F., Musen, G., \& 
Suzuki, W. A. (1993). Memory: Organization of brain systems and cognition. In D. E. Meyer \& S. Kornblum (Eds.), Attention and performance XIV (pp. 393-424). Cambridge, MA: MIT Press.

SRINIVAS, K. (1993). Perceptual specificity in nonverbal priming. Journal of Experimental Psychology: Learning, Memory, \& Cognition, 19, 582-602.

SRINIVAS, K. (1996). Size and reflection effects in priming: A test of transfer-appropriate processing. Memory \& Cognition, 24, 441-452.

Stankiewicz, B. J., Hummel, J. E., \& Cooper, E. E. (1998). The role of attention in priming for left-right reflections of object images: Evidence for a dual representation of object shape. Journal of Experimental Psychology: Human Perception \& Performance, 24, 732-744.
Treisman, A. (1992). Perceiving and re-perceiving objects. American Psychologist, 47, 862-875.

Tulving, E, \& Schacter, D. L. (1990). Priming and human memory systems. Science, 247, 301-306.

WARren, C., \& Morton, J. (1982). The effects of priming on picture recognition. British Journal of Psychology, 73, 117-129.

WELDON M. S., \& RoEdIGER, H. L., III (1987). Altering retrieval demands reverses the picture superiority effect. Memory \& Cognition, 15, 269280.

\section{(Manuscript received June 12, 2002;}

revision accepted for publication January 29, 2003.) 